\title{
Accelerated Monte Carlo Simulation for Safety Analysis of the Advanced Airspace Concept
}

\author{
David Thipphavong ${ }^{*}$ \\ NASA Ames Research Center, Moffett Field, CA, 94035
}

\begin{abstract}
Safe separation of aircraft is a primary objective of any air traffic control system. An accelerated Monte Carlo approach was developed to assess the level of safety provided by a proposed next-generation air traffic control system. It combines features of fault tree and standard Monte Carlo methods. It runs more than one order of magnitude faster than the standard Monte Carlo method while providing risk estimates that only differ by about $10 \%$. It also preserves component-level model fidelity that is difficult to maintain using the standard fault tree method. This balance of speed and fidelity allows sensitivity analysis to be completed in days instead of weeks or months with the standard Monte Carlo method. Results indicate that risk estimates are sensitive to transponder, pilot visual avoidance, and conflict detection failure probabilities.
\end{abstract}

\section{Introduction}

IR traffic demand is expected to increase substantially over the next 20 years, but controller workload limits capacity. ${ }^{1}$ It is expected that higher levels of automation for separation assurance (SA) will be required, and NASA is investigating both airborne and ground-based automation concepts to handle future demand growth ${ }^{2-3} \mathrm{~A}$ crucial step toward deployment is to assess the level of safety provided by candidate SA systems. The subject of this analysis is the Advanced Airspace Concept (AAC), a proposed ground-based next-generation air traffic control system. $^{3-5}$

Two AAC risk analysis studies have been conducted recently. The first used a fault tree approach to study four fault types: (1) nominal conditions, (2) information fault non-conformance, (3) control fault non-conformance, and (4) service interruption. ${ }^{6}$ Results of this study suggest AAC could achieve the safety levels expected in 20-30 years given the deployment of appropriately designed safety features. Although risk estimates can be computed quickly using the fault tree method, it does not facilitate component-level model fidelity because the number of conditional probabilities and failure modes grows exponentially.

The second AAC risk analysis study used a standard Monte Carlo method with fault tree style logic built into the simulation. ${ }^{7}$ In this study, each safety layer of AAC was decomposed into its hardware and software subcomponents. Critical components shared between different AAC safety layers (e.g., on-board transponder and conflict resolution maneuver readers) and common failure modes were identified. The estimated safety level of AAC in this study met the desired target for an automated separation assurance function. The standard Monte Carlo approach had a higher level of model fidelity compared to the fault tree method. However, the tradeoff was a lengthy simulation runtime of around 16 hours. As such, it is impractical to conduct a thorough sensitivity analysis using the standard Monte Carlo method.

The current study develops an accelerated Monte Carlo approach that combines features of both fault tree and standard Monte Carlo methods. The first step in this accelerated method applies the structure of the fault tree method to divide AAC into a set of six subfunctions and identify five unique failure modes. Then, the probability of each failure mode is estimated through separate smaller Monte Carlo simulations and summed up into overall probability estimates of critical events such as near mid-air collisions (NMAC) and mid-air collisions. Since AAC is a proposed next-generation system with components that are not deployed in the National Airspace System (NAS), sensitivity analysis is important to identify safety-critical components that require further study. The reductions in simulation runtime achieved using the accelerated Monte Carlo approach facilitate such sensitivity analysis.

Section II provides additional detail about AAC and the components that comprise each of its subsystems. Section III focuses on the accelerated Monte Carlo approach. Section IV compares the simulation runtime and

\footnotetext{
* Aerospace Engineer, Flight Trajectory Dynamics and Control Branch, david.p.thipphavong@nasa.gov, AIAA
} Member. 
NMAC and mid-air collision estimates for the standard and accelerated Monte Carlo approaches. Section V analyzes the sensitivity of NMAC and mid-air collision estimates to component failure probabilities using the accelerated Monte Carlo approach. Section VI discusses the results of the experiment. Section VII presents the conclusions.

\section{Background}

The Advanced Airspace Concept (AAC) is a proposed ground-based separation assurance system that monitors and maintains safe separation between aircraft automatically. Trajectory changes initiated by pilots and/or the ground system are communicated via air-ground data link. AAC includes two safety levels, Autoresolver (AR) and Tactical Separation-Assured Flight Environment (TSAFE). In addition, two safety layers already present in today's system are retained: Traffic alert Collision Avoidance System (TCAS) and visual avoidance by pilots. While AAC is responsible for resolving routine conflicts, controllers will still handle emergencies and special pilot requests. Figure 1 shows AAC's conflict detection and resolution elements and their respective action time ranges.

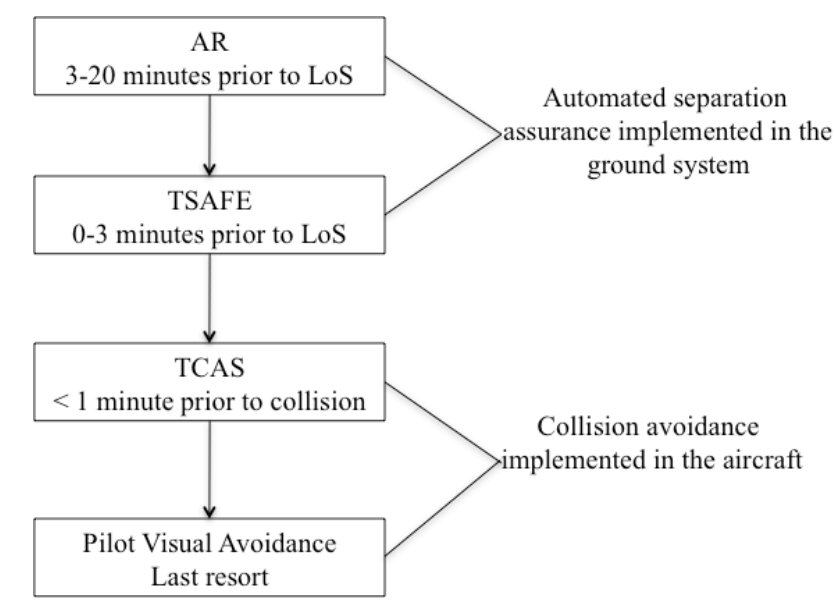

Figure 1: AAC conflict detection and resolution timeline

The Autoresolver (AR) is the workhorse of AAC. It looks ahead three to twenty minutes to detect and prevent losses of separation (LoS), defined as separation of less than five nautical miles (nmi) of horizontally and 1000 feet (ft) vertically. Its purpose is to handle nearly all conflicts that arise. It receives a continual feed of positional data for flights via radar and Global Positioning System (GPS) units onboard most aircraft, from which it generates trajectory predictions. Its conflict detection function probes predicted trajectories two-at-a-time for all pairs of flights in the region of airspace for which it is responsible. Then, its conflict resolution algorithm searches for trajectories predicted to be conflict-free for at least 20 minutes in the future. Fast-time simulations of AR indicate it can handle the full breadth and variety of conflict situations that occur in enroute airspace including climbs and descents to arrival fixes at up to three times current traffic levels. ${ }^{8-9}$

TSAFE is the primary backup system to AR and is also implemented on the ground. Its purpose is to detect and resolve conflicts in the shorter tactical time horizon of zero to three minutes prior to LoS that were not detected or were not resolved by AR at an earlier time to LoS. ${ }^{10-12}$ As such, it is designed to be simpler than AR and places higher priority on safety over efficiency. TSAFE is an autonomous system on the ground that runs in parallel to AR and relies on the same data. As such, it has more accurate resolutions compared to TCAS (described below). However, it is similar to TCAS in using on-board voice synthesizers to issue heading or altitude changes to pilots.

TCAS is the safety net beneath AR and TSAFE. It is an airborne collision avoidance system that is independent of both onboard navigation equipment and ground-based air traffic control systems including AR and TSAFE. ${ }^{13}$ Each TCAS-equipped aircraft interrogates nearby aircraft about their respective current altitudes and also responds with its own altitude when interrogated. Each individual aircraft's TCAS system repeats the interrogation process continually to determine the range of nearby aircraft. An on-board computer analyzes the data to generate collision avoidance maneuvers. Resolution advisories (climb or descend) are issued via cockpit display and synthesized voice commands.

Visual detection and avoidance by the pilot constitute the final safety layer. This is the last resort if the other automated separation assurance systems are all unable to detect and resolve an impending collision 


\section{Accelerated Monte Carlo Simulation Approach}

This section describes the accelerated Monte Carlo simulation method for a safety analysis of AAC. It combines features of both fault tree and standard Monte Carlo methods. The accelerated Monte Carlo approach first applies the structure of the fault tree method to divide AAC into six distinct subfunctions and identify five unique failure modes. Then, the probability of each failure mode is rewritten as a product of several conditional probabilities using analogues of Bayes' Theorem. After that, each failure mode probability is estimated using Monte Carlo simulations of reduced complexity.

\section{A. Simulation Assumptions and Simplifications}

The simulations conducted in this study are derived from those run in a prior safety analysis of AAC. ${ }^{7}$ As such, all assumptions and simplifications made in the previous study are also present here. They must be examined more closely because they can affect the estimates of NMAC (defined as separation of less than $500 \mathrm{ft}$ vertically and 100 $\mathrm{ft}$ horizontally ${ }^{6}$ ) and collision risk. An abridged list of the most important ones is given below:

- In the absence of any SA systems, NMACs are independent, identically distributed events.

- AAC component failures are independent and identically distributed.

- Average flight time is two hours.

- Flights are locatable either via Automatic Dependent Surveillance-Broadcast (ADS-B) or Secondary Surveillance Radar (SSR), but primary radar is not used.

- Maximum look-ahead time for conflict detection and resolution is eight minutes.

- AR and TSAFE perform conflict detection and resolution and issue maneuvers in 30-second intervals.

- Component failures are not relevant to the simulation unless they occur within eight minutes prior to NMAC. Otherwise, it is assumed that failure monitors will identify failures and perform mitigating actions.

- Component failures are only in effect if they occur between eight minutes prior to NMAC and the current time step in the simulation.

- Probability of detecting a conflict only depends on look-ahead time (e.g., phase of flight is not a factor).

- If a conflict-free resolution is found and successfully communicated, it is executed correctly, resolves the conflict in all traffic situations, and there is no conflict between the same flight pair in the future.

- Flights are equipped with ADS-B and TCAS Version II.

\section{B. Subfunction Identification}

The first step in the standard Monte Carlo risk analysis of AAC was to decompose each safety layer in Figure 1 into its respective hardware, software, and functional subcomponents. ${ }^{7}$ (See the Appendix for fault tree diagrams and descriptions and failure probabilities of these components.) In the accelerated Monte Carlo approach, the first step is to gather them into subfunctions. Simulation runtime is minimized by minimizing the number of subfunctions necessary to capture all failure modes possible in the standard Monte Carlo method. Analysis indicated that this could be achieved with six subfunctions: 1) flight locatability, 2) AR conflict detection, 3) AR conflict resolution and communication, 4) TSAFE conflict detection, 5) TSAFE resolution and communication, and 6) TCAS and pilot visual avoidance. (See Table 1 for subfunction abbreviations.)

\begin{tabular}{|c|c|}
\hline Subfunction & Abbreviation \\
\hline Flight locatability (via ADS-B or SSR) & $\mathrm{L}$ \\
\hline AR conflict detection & $\mathrm{S}_{\mathrm{d}}$ \\
\hline AR conflict resolution and communication & $\mathrm{S}_{\mathrm{r}}$ \\
\hline TSAFE conflict detection & $\mathrm{T}_{\mathrm{d}}$ \\
\hline TSAFE conflict resolution and communication & $\mathrm{T}_{\mathrm{r}}$ \\
\hline TCAS and pilot visual avoidance & $\mathrm{A}$ \\
\hline
\end{tabular}

Table 1: AAC subfunctions

\section{Failure Mode Identification}

Using the fault tree method, five unique failure modes were identified for these six subfunctions. All involve TCAS not functioning on at least one flight and:

- At least one flight not locatable via either ADS-B or SSR, or 
- Both flights are locatable and the conflict is detected by AR and TSAFE, but both AR and TSAFE cannot find or communicate a conflict-free resolution, or

- Both flights are locatable and detected by AR, but a conflict-free AR resolution could not be found or communicated, and the conflict was not detected by TSAFE, or

- Both flights are locatable but the conflict is only detected by TSAFE and a conflict-free TSAFE resolution was not found or communicated, or

- Both flights are locatable, but AR and TSAFE do not detect the conflict.

These five failure modes are represented in Table 2. Green boxes are AAC subfunctions that are operational in the given failure mode. By contrast, red boxes denote failed subfunctions. Red arrows indicate how failure of one subfunction (arrow's origin) also causes another subfunction downstream to fail (arrow's destination). For instance, failure mode 5 consists of cases where both flights are locatable. However, since AR does not detect the conflict in this failure mode, no strategic AR resolution is found or communicated. Similarly, since TSAFE does not detect the conflict, no tactical TSAFE resolution is issued. Lastly, as in all failure modes, TCAS and pilot visual avoidance do not detect and avoid the NMAC, which also has a chance of ending up as a mid-air collision.

\begin{tabular}{|c|c|c|c|c|c|c|}
\hline $\begin{array}{c}\text { Failure } \\
\text { Mode }\end{array}$ & Locatable & $\begin{array}{c}\text { Strategic } \\
\text { Detection }\end{array}$ & $\begin{array}{c}\text { Strategic } \\
\text { Resolution }\end{array}$ & $\begin{array}{c}\text { Tactical } \\
\text { Detection }\end{array}$ & $\begin{array}{c}\text { Tactical } \\
\text { Resolution }\end{array}$ & TCAS/Pilot \\
\hline 1 & & & & & & \\
\hline 2 & & & & & $\longrightarrow$ & \\
\hline 3 & & & & & & \\
\hline 4 & & & $\longrightarrow$ & & & \\
\hline 5 & & & & & & \\
\hline
\end{tabular}

Table 2: Component states in failure modes (accelerated Monte Carlo)

Table 3 contains two sets of equations derived from these failure modes that are used to estimate the rate of NMACs and collisions, respectively. The only difference between them is a "C" term in the latter set of equations for the event of collision.

\begin{tabular}{|c|l|l|}
\hline $\begin{array}{c}\text { Failure mode } \\
\text { number }\end{array}$ & \multicolumn{1}{|c|}{ Probability of NMAC } & \multicolumn{1}{|c|}{ Probability of collision } \\
\hline 1 & $\mathrm{P}\left(\mathrm{N}_{1}\right)=\mathrm{P}\left(\mathrm{L}^{\prime}, \mathrm{A}^{\prime}\right)$ & $\mathrm{P}\left(\mathrm{C}_{1}\right)=\mathrm{P}\left(\mathrm{C}, \mathrm{L}^{\prime}, \mathrm{A}^{\prime}\right)$ \\
\hline 2 & $\mathrm{P}\left(\mathrm{N}_{2}\right)=\mathrm{P}\left(\mathrm{L}, \mathrm{S}_{\mathrm{d}}, \mathrm{S}_{\mathrm{r}}{ }^{\prime}, \mathrm{T}_{\mathrm{d}}, \mathrm{T}_{\mathrm{r}}{ }^{\prime}, \mathrm{A}^{\prime}\right)$ & $\mathrm{P}\left(\mathrm{C}_{2}\right)=\mathrm{P}\left(\mathrm{C}, \mathrm{L}, \mathrm{S}_{\mathrm{d}}, \mathrm{S}_{\mathrm{r}}, \mathrm{T}_{\mathrm{d}}, \mathrm{T}_{\mathrm{r}}, \mathrm{A}^{\prime}\right)$ \\
\hline 3 & $\mathrm{P}\left(\mathrm{N}_{3}\right)=\mathrm{P}\left(\mathrm{L}, \mathrm{S}_{\mathrm{d}}, \mathrm{S}_{\mathrm{r}}{ }^{\prime}, \mathrm{T}_{\mathrm{d}}{ }^{\prime}, \mathrm{A}^{\prime}\right)$ & $\mathrm{P}\left(\mathrm{C}_{3}\right)=\mathrm{P}\left(\mathrm{C}, \mathrm{L}, \mathrm{S}_{\mathrm{d}}, \mathrm{S}_{\mathrm{r}}{ }^{\prime}, \mathrm{T}_{\mathrm{d}}{ }^{\prime}, \mathrm{A}^{\prime}\right)$ \\
\hline 4 & $\mathrm{P}\left(\mathrm{N}_{4}\right)=\mathrm{P}\left(\mathrm{L}, \mathrm{S}_{\mathrm{d}}{ }^{\prime}, \mathrm{T}_{\mathrm{d}}, \mathrm{T}_{\mathrm{r}}{ }^{\prime}, \mathrm{A}^{\prime}\right)$ & $\mathrm{P}\left(\mathrm{C}_{4}\right)=\mathrm{P}\left(\mathrm{C}, \mathrm{L}, \mathrm{S}_{\mathrm{d}}{ }^{\prime}, \mathrm{T}_{\mathrm{d}}, \mathrm{T}_{\mathrm{r}}{ }^{\prime}, \mathrm{A}^{\prime}\right)$ \\
\hline 5 & $\mathrm{P}\left(\mathrm{N}_{5}\right)=\mathrm{P}\left(\mathrm{L}, \mathrm{S}_{\mathrm{d}}{ }^{\prime}, \mathrm{T}_{\mathrm{d}}{ }^{\prime}, \mathrm{A}^{\prime}\right)$ & $\mathrm{P}\left(\mathrm{C}_{5}\right)=\mathrm{P}\left(\mathrm{C}, \mathrm{L}, \mathrm{S}_{\mathrm{d}}{ }^{\prime}, \mathrm{T}_{\mathrm{d}}{ }^{\prime}, \mathrm{A}^{\prime}\right)$ \\
\hline Total & $\mathrm{P}(\mathrm{N})=\mathrm{P}\left(\mathrm{N}_{1}{ }^{\prime}\right)+\mathrm{P}\left(\mathrm{N}_{2}\right)+\mathrm{P}\left(\mathrm{N}_{3}\right)+\mathrm{P}\left(\mathrm{N}_{4}\right)+\mathrm{P}\left(\mathrm{N}_{5}\right)$ & $\mathrm{P}(\mathrm{C})=\mathrm{P}\left(\mathrm{C}_{1}\right)+\mathrm{P}\left(\mathrm{C}_{2}\right)+\mathrm{P}\left(\mathrm{C}_{3}\right)+\mathrm{P}\left(\mathrm{C}_{4}\right)+\mathrm{P}\left(\mathrm{C}_{5}\right)$ \\
\hline
\end{tabular}

Table 3: Failure mode equations

\section{Failure Mode Decomposition}

Each failure mode was rewritten using analogues of Bayes' Theorem as shown in Tables 4-5 for NMAC and collision, respectively. Each term in these equations is simulated from left to right using the results of the preceding simulation as a set of possible initial conditions for the next one. This eliminates the need to step through billions of simulation trials one at a time as in the standard Monte Carlo method. In this respect, the accelerated Monte Carlo method is similar to recent studies that used rare event Monte Carlo simulation to estimate the collision risk of an uncoordinated airborne self-separation concept. ${ }^{14-15}$

Consider failure mode 1 . The first step in estimating its probability is to simulate the likelihood that at least one flight is not locatable via ADS-B or SSR in a Monte Carlo simulation. The result is an estimated value for P(L') and a set of "non-locatable" cases.

The next step is to estimate the probability that TCAS and pilots fail to avoid the NMAC given that at least one flight is not locatable via ADS-B or SSR. At the start of each Monte Carlo simulation trial, one "non-locatable" case identified in the first step is selected at random and used as the initial conditions. The end result of the simulation 
trial is an estimated value for $\mathrm{P}\left(\mathrm{A}^{\prime} \mid \mathrm{L}^{\prime}\right)$. The probability of $\mathrm{NMAC}$ in failure mode 1 is then computed as the product of $\mathrm{P}\left(\mathrm{L}^{\prime}\right)$ and $\mathrm{P}\left(\mathrm{A}^{\prime} \mid \mathrm{L}^{\prime}\right)$ as shown in Table 4 . The probability of collision (see Table 5) can be estimated using the set of "non-locatable and TCAS and pilot visual avoidance failure" cases as initial conditions in a similar way.

\begin{tabular}{|c|l|}
\hline $\begin{array}{c}\text { Failure } \\
\text { mode }\end{array}$ & \multicolumn{1}{|c|}{ Failure mode probability of NMAC } \\
\hline $\mathrm{N}_{1}$ & $\mathrm{P}\left(\mathrm{N}_{1}\right)=\mathrm{P}\left(\mathrm{L}^{\prime}\right) \cdot \mathrm{P}\left(\mathrm{A}^{\prime} \mid \mathrm{L}^{\prime}\right)$ \\
\hline $\mathrm{N}_{2}$ & $\mathrm{P}\left(\mathrm{N}_{2}\right)=\mathrm{P}(\mathrm{L}) \cdot \mathrm{P}\left(\mathrm{S}_{\mathrm{d}}, \mathrm{S}_{\mathrm{r}}{ }^{\prime} \mid \mathrm{L}\right) \cdot \mathrm{P}\left(\mathrm{T}_{\mathrm{d}}, \mathrm{T}_{\mathrm{r}}{ }^{\prime} \mid \mathrm{S}_{\mathrm{r}}{ }^{\prime}, \mathrm{S}_{\mathrm{d}}, \mathrm{L}\right) \cdot \mathrm{P}\left(\mathrm{A}^{\prime} \mid \mathrm{T}_{\mathrm{r}}{ }^{\prime}, \mathrm{T}_{\mathrm{d}}, \mathrm{S}_{\mathrm{r}}{ }^{\prime}, \mathrm{S}_{\mathrm{d}}, \mathrm{L}\right)$ \\
\hline $\mathrm{N}_{3}$ & $\mathrm{P}\left(\mathrm{N}_{3}\right)=\mathrm{P}(\mathrm{L}) \cdot \mathrm{P}\left(\mathrm{S}_{\mathrm{d}}, \mathrm{S}_{\mathrm{r}}{ }^{\prime} \mid \mathrm{L}\right) \cdot \mathrm{P}\left(\mathrm{T}_{\mathrm{d}}{ }^{\prime} \mid \mathrm{S}_{\mathrm{r}}, \mathrm{S}_{\mathrm{d}}, \mathrm{L}\right) \cdot \mathrm{P}\left(\mathrm{A}^{\prime} \mid \mathrm{T}_{\mathrm{d}}, \mathrm{S}_{\mathrm{r}}{ }^{\prime}, \mathrm{S}_{\mathrm{d}}, \mathrm{L}\right)$ \\
\hline $\mathrm{N}_{4}$ & $\mathrm{P}\left(\mathrm{N}_{4}\right)=\mathrm{P}(\mathrm{L}) \cdot \mathrm{P}\left(\mathrm{S}_{\mathrm{d}}{ }^{\prime} \mid \mathrm{L}\right) \cdot \mathrm{P}\left(\mathrm{T}_{\mathrm{d}}, \mathrm{T}_{\mathrm{r}}{ }^{\prime} \mid \mathrm{S}_{\mathrm{d}}{ }^{\prime}, \mathrm{L}\right) \cdot \mathrm{P}\left(\mathrm{A}^{\prime} \mid \mathrm{T}_{\mathrm{r}}{ }^{\prime}, \mathrm{T}_{\mathrm{d}}, \mathrm{S}_{\mathrm{d}}{ }^{\prime}, \mathrm{L}\right)$ \\
\hline $\mathrm{N}_{5}$ & $\mathrm{P}\left(\mathrm{N}_{5}\right)=\mathrm{P}(\mathrm{L}) \cdot \mathrm{P}\left(\mathrm{S}_{\mathrm{d}}{ }^{\prime} \mid \mathrm{L}\right) \cdot \mathrm{P}\left(\mathrm{T}_{\mathrm{d}}{ }^{\prime} \mid \mathrm{S}_{\mathrm{d}}{ }^{\prime}, \mathrm{L}\right) \cdot \mathrm{P}\left(\mathrm{A}^{\prime} \mid \mathrm{T}_{\mathrm{d}}{ }^{\prime}, \mathrm{S}_{\mathrm{d}}{ }^{\prime}, \mathrm{L}\right)$ \\
\hline Total & $\mathrm{P}(\mathrm{N})=\mathrm{P}\left(\mathrm{N}_{1}\right)+\mathrm{P}\left(\mathrm{N}_{2}\right)+\mathrm{P}\left(\mathrm{N}_{3}\right)+\mathrm{P}\left(\mathrm{N}_{4}\right)+\mathrm{P}\left(\mathrm{N}_{5}\right)$ \\
\hline
\end{tabular}

Table 4: Bayes' theorem decomposition of failure modes for NMAC

\begin{tabular}{|c|l|}
\hline $\begin{array}{c}\text { Failure } \\
\text { mode }\end{array}$ & \multicolumn{1}{c|}{ Failure mode probability of collision } \\
\hline $\mathrm{C}_{1}$ & $\mathrm{P}\left(\mathrm{C}_{1}\right)=\mathrm{P}\left(\mathrm{L}^{\prime}\right) \cdot \mathrm{P}\left(\mathrm{A}^{\prime} \mid \mathrm{L}^{\prime}\right) \cdot \mathrm{P}\left(\mathrm{C} \mid \mathrm{A}^{\prime}, \mathrm{L}^{\prime}\right)$ \\
\hline $\mathrm{C}_{2}$ & $\mathrm{P}\left(\mathrm{C}_{2}\right)=\mathrm{P}(\mathrm{L}) \cdot \mathrm{P}\left(\mathrm{S}_{\mathrm{d}}, \mathrm{S}_{\mathrm{r}}{ }^{\prime} \mid \mathrm{L}\right) \cdot \mathrm{P}\left(\mathrm{T}_{\mathrm{d}}, \mathrm{T}_{\mathrm{r}}{ }^{\prime} \mid \mathrm{S}_{\mathrm{r}}{ }^{\prime}, \mathrm{S}_{\mathrm{d}}, \mathrm{L}\right) \cdot \mathrm{P}\left(\mathrm{A}^{\prime} \mid \mathrm{T}_{\mathrm{r}}{ }^{\prime}, \mathrm{T}_{\mathrm{d}}, \mathrm{S}_{\mathrm{r}}{ }^{\prime}, \mathrm{S}_{\mathrm{d}}, \mathrm{L}\right) \cdot \mathrm{P}\left(\mathrm{C} \mid \mathrm{A}^{\prime}, \mathrm{T}_{\mathrm{r}}{ }^{\prime}, \mathrm{T}_{\mathrm{d}}, \mathrm{S}_{\mathrm{r}}{ }^{\prime}, \mathrm{S}_{\mathrm{d}}, \mathrm{L}\right)$ \\
\hline $\mathrm{C}_{3}$ & $\mathrm{P}\left(\mathrm{C}_{3}\right)=\mathrm{P}(\mathrm{L}) \cdot \mathrm{P}\left(\mathrm{S}_{\mathrm{d}}, \mathrm{S}_{\mathrm{r}}{ }^{\prime} \mid \mathrm{L}\right) \cdot \mathrm{P}\left(\mathrm{T}_{\mathrm{d}}{ }^{\prime} \mid \mathrm{S}_{\mathrm{r}}{ }^{\prime}, \mathrm{S}_{\mathrm{d}}, \mathrm{L}\right) \cdot \mathrm{P}\left(\mathrm{A}^{\prime} \mid \mathrm{T}_{\mathrm{d}}, \mathrm{S}_{\mathrm{r}}{ }^{\prime}, \mathrm{S}_{\mathrm{d}}, \mathrm{L}\right) \cdot \mathrm{P}\left(\mathrm{C} \mid \mathrm{A}^{\prime}, \mathrm{T}_{\mathrm{d}}, \mathrm{S}_{\mathrm{r}}{ }^{\prime}, \mathrm{S}_{\mathrm{d}}, \mathrm{L}\right)$ \\
\hline $\mathrm{C}_{4}$ & $\mathrm{P}\left(\mathrm{C}_{4}\right)=\mathrm{P}(\mathrm{L}) \cdot \mathrm{P}\left(\mathrm{S}_{\mathrm{d}}{ }^{\prime} \mid \mathrm{L}\right) \cdot \mathrm{P}\left(\mathrm{T}_{\mathrm{d}}, \mathrm{T}_{\mathrm{r}}{ }^{\prime} \mid \mathrm{S}_{\mathrm{d}}{ }^{\prime}, \mathrm{L}\right) \cdot \mathrm{P}\left(\mathrm{A}^{\prime} \mid \mathrm{T}_{\mathrm{r}}{ }^{\prime}, \mathrm{T}_{\mathrm{d}}, \mathrm{S}_{\mathrm{d}}{ }^{\prime}, \mathrm{L}\right) \cdot \mathrm{P}\left(\mathrm{C} \mid \mathrm{A}^{\prime}, \mathrm{T}_{\mathrm{r}}{ }^{\prime}, \mathrm{T}_{\mathrm{d}}, \mathrm{S}_{\mathrm{d}}{ }^{\prime}, \mathrm{L}\right)$ \\
\hline $\mathrm{C}_{5}$ & $\mathrm{P}\left(\mathrm{C}_{5}\right)=\mathrm{P}(\mathrm{L}) \cdot \mathrm{P}\left(\mathrm{S}_{\mathrm{d}}{ }^{\prime} \mid \mathrm{L}\right) \cdot \mathrm{P}\left(\mathrm{T}_{\mathrm{d}}{ }^{\prime} \mid \mathrm{S}_{\mathrm{d}}{ }^{\prime}, \mathrm{L}\right) \cdot \mathrm{P}\left(\mathrm{A}^{\prime} \mid \mathrm{T}_{\mathrm{d}}{ }^{\prime}, \mathrm{S}_{\mathrm{d}}{ }^{\prime}, \mathrm{L}\right) \cdot \mathrm{P}\left(\mathrm{C} \mid \mathrm{A}^{\prime}, \mathrm{T}_{\mathrm{d}}{ }^{\prime}, \mathrm{S}_{\mathrm{d}}{ }^{\prime}, \mathrm{L}\right)$ \\
\hline Total & $\mathrm{P}(\mathrm{C})=\mathrm{P}\left(\mathrm{C}_{1}\right)+\mathrm{P}\left(\mathrm{C}_{2}\right)+\mathrm{P}\left(\mathrm{C}_{3}\right)+\mathrm{P}\left(\mathrm{C}_{4}\right)+\mathrm{P}\left(\mathrm{C}_{5}\right)$ \\
\hline
\end{tabular}

Table 5: Bayes' theorem decomposition of failure modes for collision

Note that some AAC subfunctions are grouped together and simulated at the same time. For instance, probability estimates for AR detection and resolution come from a single simulation; this was also the case for the probability estimates for TSAFE detection and resolution. This is because both conflict detection and resolution are performed in sequence at regular intervals in both AR and TSAFE.

Note that the number of simulations needed is less than the number of factors shown in Tables 4 and 5 since several factors are shared by multiple failure modes (e.g., $\mathrm{P}(\mathrm{L})$ ). As such, only one simulation run for that factor is necessary. In some cases, multiple factors can be estimated in the same simulation. For instance, in simulation trials to estimate $\mathrm{P}(\mathrm{L})$, only two possible outcomes are possible: 1) both flights are locatable, or 2) at least one flight is not locatable. As a result, estimates of both $\mathrm{P}(\mathrm{L})$ and its complement $\mathrm{P}\left(\mathrm{L}^{\prime}\right)=1-\mathrm{P}(\mathrm{L})$ come from the same simulation. It turns out that the five failure mode probabilities can be estimated with a total of just nine Monte Carlo simulations.

\section{Simulation Results}

This section compares simulation results for the accelerated and standard Monte Carlo methods. All simulations were performed using Java on the same machine with a dual-core processor and clock speed of $3.06 \mathrm{GHz}$ and $8 \mathrm{~GB}$ of memory. Simulation parameters including component failure probabilities can be found in the Appendix.

The accelerated Monte Carlo approach is designed to reduce simulation runtime while maintaining componentlevel fidelity. As such, the simulation runtimes and estimates of NMAC and collision risk are compared for both the standard and the accelerated Monte Carlo methods.

\section{A. Runtime Comparison}

In the case of the standard Monte Carlo simulation with ten billion trials, total runtime was 15.7 hours. Although performing fewer simulation trials can reduce runtime, it will also result in unacceptably small sample sizes for rare safety-critical events such as NMACs and collisions.

The accelerated Monte Carlo approach ran in just 4\% of the time needed by the standard Monte Carlo method. A breakdown of the nine simpler Monte Carlo simulations performed can be found in the last column of Table 6 . The first column indicates the AAC component that was simulated. The next six columns indicate the state of the other AAC subfunctions in the set of possible initial conditions. As in Table 2, green boxes indicate subfunctions that are operational, and red boxes denote those that have failed. White boxes are ones that have not yet been simulated. 


\begin{tabular}{|c|c|c|c|c|c|c|c|}
\hline \multirow{2}{*}{$\begin{array}{c}\text { Simulated } \\
\text { component }\end{array}$} & \multicolumn{5}{|c|}{ Initial conditions } & \multirow{2}{*}{ Runtime (min) } \\
\cline { 2 - 6 } & $\mathbf{L}$ & $\mathbf{S}_{\mathbf{d}}$ & $\mathbf{S}_{\mathbf{r}}$ & $\mathbf{T}_{\mathbf{d}}$ & $\mathbf{T}_{\mathbf{r}}$ & $\mathbf{A}$ & \\
\hline Aircraft Locatability & & & & & & & 2.8 \\
\hline Strategic (AR) & & & & & & & 15.1 \\
\hline Tactical (TSAFE) & & & & & & & 9.5 \\
\hline Tactical (TSAFE) & & & & & & & 11.2 \\
\hline TCAS/Pilot/C & & & & & & & 0.0 \\
\hline TCAS/Pilot/C & & & & & & & 0.0 \\
\hline TCAS/Pilot/C & & & & & & & 0.0 \\
\hline TCAS/Pilot/C & & & & & & & 0.0 \\
\hline TCAS/Pilot/C & & & & & & & 0.0 \\
\hline Total & & & & \\
\hline
\end{tabular}

Table 6: Breakdown of simulation runtimes (accelerated Monte Carlo)

\section{B. Risk Estimate Comparison}

The reductions in runtime that could be achieved in the accelerated Monte Carlo approach are not of value unless its NMAC and collision risk estimates are similar to those using the standard Monte Carlo method. The fraction of simulation trials that experienced NMAC in ten billion trials in the standard Monte Carlo approach was $2.6 \cdot 10^{-8}$. By comparison, the accelerated Monte Carlo approach had an NMAC estimate of $2.9 \cdot 10^{-8}$, which is a difference of about $11 \%$. See Table 7 for detailed failure mode estimates.

\begin{tabular}{|c|c|c|}
\hline Failure Mode & Probability description & Probability \\
\hline $\mathrm{N}_{1}$ & $\mathrm{P}\left(\mathrm{N}_{1}\right)=\mathrm{P}\left(\mathrm{L}^{\prime}, \mathrm{A}^{\prime}\right)$ & $2.7 \cdot 10^{-8}$ \\
\hline $\mathrm{N}_{2}$ & $\mathrm{P}\left(\mathrm{N}_{2}\right)=\mathrm{P}\left(\mathrm{L}, \mathrm{S}_{\mathrm{d}}, \mathrm{S}_{\mathrm{r}}{ }^{\prime}, \mathrm{T}_{\mathrm{d}}, \mathrm{T}_{\mathrm{r}}{ }^{\prime}, \mathrm{A}^{\prime}\right)$ & $3.9 \cdot 10^{-14}$ \\
\hline $\mathrm{N}_{3}$ & $\mathrm{P}\left(\mathrm{N}_{3}\right)=\mathrm{P}\left(\mathrm{L}, \mathrm{S}_{\mathrm{d}}, \mathrm{S}_{\mathrm{r}}{ }^{\prime}, \mathrm{T}_{\mathrm{d}}{ }^{\prime}, \mathrm{A}^{\prime}\right)$ & $6.6 \cdot 10^{-12}$ \\
\hline $\mathrm{N}_{4}$ & $\mathrm{P}\left(\mathrm{N}_{4}\right)=\mathrm{P}\left(\mathrm{L}, \mathrm{S}_{\mathrm{d}^{\prime}}, \mathrm{T}_{\mathrm{d}}, \mathrm{T}_{\mathrm{r}}{ }^{\prime}, \mathrm{A}^{\prime}\right)$ & $8.5 \cdot 10^{-12}$ \\
\hline $\mathrm{N}_{5}$ & $\mathrm{P}\left(\mathrm{N}_{5}\right)=\mathrm{P}\left(\mathrm{L}, \mathrm{S}_{\mathrm{d}}{ }^{\prime}, \mathrm{T}_{\mathrm{d}}, \mathrm{A}^{\prime}\right)$ & $1.7 \cdot 10^{-9}$ \\
\hline Total & $\mathrm{P}(\mathrm{N})=\mathrm{P}\left(\mathrm{N}_{1}\right)+\mathrm{P}\left(\mathrm{N}_{2}\right)+\mathrm{P}\left(\mathrm{N}_{3}\right)+\mathrm{P}\left(\mathrm{N}_{4}\right)+\mathrm{P}\left(\mathrm{N}_{5}\right)$ & $2.9 \cdot 10^{-8}$ \\
\hline
\end{tabular}

Table 7: NMAC probability estimates by failure mode (accelerated Monte Carlo)

The collision probability estimates were also similar (see Table 8). The standard Monte Carlo simulation with ten billion trials had a collision probability estimate of $8.9 \cdot 10^{-9}$. By comparison, the estimated collision probability using the accelerated Monte Carlo approach was $9.7 \cdot 10^{-9}$, which is a difference of about $9 \%$.

\begin{tabular}{|c|c|c|}
\hline Failure Mode & Probability description & Probability \\
\hline $\mathrm{C}_{1}$ & $\mathrm{P}\left(\mathrm{C}_{1}\right)=\mathrm{P}\left(\mathrm{C}, \mathrm{L}^{\prime}, \mathrm{A}^{\prime}\right)$ & $9.0 \cdot 10^{-9}$ \\
\hline $\mathrm{C}_{2}$ & $\mathrm{P}\left(\mathrm{C}_{2}\right)=\mathrm{P}\left(\mathrm{C}, \mathrm{L}, \mathrm{S}_{\mathrm{d}}, \mathrm{S}_{\mathrm{r}}{ }^{\prime}, \mathrm{T}_{\mathrm{d}}, \mathrm{T}_{\mathrm{r}}{ }^{\prime}, \mathrm{A}^{\prime}\right)$ & $1.4 \cdot 10^{-14}$ \\
\hline $\mathrm{C}_{3}$ & $\mathrm{P}\left(\mathrm{C}_{3}\right)=\mathrm{P}\left(\mathrm{C}, \mathrm{L}, \mathrm{S}_{\mathrm{d}}, \mathrm{S}_{\mathrm{r}}{ }^{\prime}, \mathrm{T}_{\mathrm{d}}{ }^{\prime}, \mathrm{A}^{\prime}\right)$ & $2.5 \cdot 10^{-12}$ \\
\hline $\mathrm{C}_{4}$ & $\mathrm{P}\left(\mathrm{C}_{4}\right)=\mathrm{P}\left(\mathrm{C}, \mathrm{L}, \mathrm{S}_{\mathrm{d}^{\prime}}{ }^{\prime}, \mathrm{T}_{\mathrm{d}}, \mathrm{T}_{\mathrm{r}}{ }^{\prime}, \mathrm{A}^{\prime}\right)$ & $3.3 \cdot 10^{-12}$ \\
\hline $\mathrm{C}_{5}$ & $\mathrm{P}\left(\mathrm{C}_{5}\right)=\mathrm{P}\left(\mathrm{C}, \mathrm{L}, \mathrm{S}_{\mathrm{d}^{\prime}}{ }^{\prime}, \mathrm{T}_{\mathrm{d}}{ }^{\prime}, \mathrm{A}^{\prime}\right)$ & $6.0 \cdot 10^{-10}$ \\
\hline Total & $\mathrm{P}(\mathrm{C})=\mathrm{P}\left(\mathrm{C}_{1}\right)+\mathrm{P}\left(\mathrm{C}_{2}\right)+\mathrm{P}\left(\mathrm{C}_{3}\right)+\mathrm{P}\left(\mathrm{C}_{4}\right)+\mathrm{P}\left(\mathrm{C}_{5}\right)$ & $9.7 \cdot 10^{-9}$ \\
\hline
\end{tabular}

Table 8: Collision probability estimates by failure mode (accelerated Monte Carlo)

Additional Monte Carlo simulations were needed to estimate the time between NMACs and mid-air collisions based on the probability estimates in Tables 7 and 8 . This took another 24 minutes, which resulted in an overall simulation runtime of 63 minutes. This is equal to about $7 \%$ of the runtime required by the standard Monte Carlo method.

Results from these simulations are presented in Table 9. The estimated mean time between NMACs and collisions using the accelerated Monte Carlo approach is about $10 \%$ less than estimates using the standard Monte 
Carlo method. These results were as expected because the NMAC and collision probability estimates also differed by about $10 \%$.

\begin{tabular}{|c|c|c|c|c|}
\hline & \multicolumn{2}{|c|}{ NMAC } & \multicolumn{2}{c|}{ Collision } \\
\hline & Accelerated & Standard & Accelerated & Standard \\
\hline $\begin{array}{c}\text { Number of trials } \\
\text { (out of 10 billion) }\end{array}$ & 291 & 262 & 103 & 89 \\
\hline $\begin{array}{c}\text { Mean time between } \\
\text { events }\end{array}$ & 87 years & 96 years & 246 years & 281 years \\
\hline $\begin{array}{c}\text { Sample standard } \\
\text { deviation of time } \\
\text { between events }\end{array}$ & 84 years & 96 years & 243 years & 244 years \\
\hline
\end{tabular}

Table 9: Estimates of time between NMACs and mid-air collisions

\section{Sensitivity Analysis}

The similarity of NMAC and collision risk estimates using the standard and accelerated Monte Carlo approaches indicates that the latter can be used for sensitivity analysis. This was previously identified as a topic for future AAC risk analysis research. ${ }^{7}$ This can be useful for identifying safety-critical components of AAC that require further study, especially those that are not deployed in today's NAS. The results of a limited sensitivity analysis using the accelerated Monte Carlo approach are presented below.

Sensitivity analysis was first performed on components that are common to multiple failure modes: 1) mode $S$ transponder, 2) resolution reader, and 3) speaker failure. Failure probabilities were changed by one and two orders of magnitude. The estimated risk of NMACs and collisions did not change much for the latter two components; NMAC estimates remained between 70 and 100 years, and collision estimates stayed between 200 and 300 years. By comparison, they were noticeably sensitive to changes in transponder failure as expected (see Table 10). This is because its nominal failure probability is one of the highest in the model, and it is used for locatability via ADS-B and SSR as well as by TSAFE and TCAS. This indicates that additional research to get more accurate transponder failure probability is needed.

\begin{tabular}{|l|c|c|c|c|c|}
\hline Failure probability & \multicolumn{2}{|c|}{ Time between NMACs (yrs) } & \multicolumn{2}{|c|}{ Time between collisions (yrs) } & Runtime (min) \\
\hline & Mean & $\begin{array}{c}\text { Standard } \\
\text { Deviation }\end{array}$ & Mean & $\begin{array}{c}\text { Standard } \\
\text { Deviation }\end{array}$ & \\
\hline Nominal P(RT) & 87 & 84 & 246 & 243 & 62.6 \\
\hline Nominal P(RT) 10 & 53 & 55 & 157 & 161 & 58.0 \\
\hline Nominal P(RT) 100 & 3 & 3 & 10 & 11 & 55.6 \\
\hline
\end{tabular}

Table 10: Mode $S$ transponder sensitivity analysis results

Sensitivity analysis was also performed on the failure probability of pilot visual avoidance, and the probability of mid-air collision given NMAC. This is because they directly affect the proportion of conflicts not resolved by AR, TSAFE, or TCAS that become NMACs and mid-air collisions. As expected, the risk estimates for both NMAC and mid-air collision events were found to be sensitive (see Tables 11 and 12). As such, the failure probability of pilot visual avoidance and the probability of mid-air collision given NMAC also require additional investigation.

\begin{tabular}{|l|c|c|c|c|c|}
\hline Failure probability & \multicolumn{2}{|c|}{ Time between NMACs (yrs) } & \multicolumn{2}{c|}{ Time between collisions (yrs) } & Runtime (min) \\
\hline & Mean & $\begin{array}{c}\text { Standard } \\
\text { Deviation }\end{array}$ & Mean & $\begin{array}{c}\text { Standard } \\
\text { Deviation }\end{array}$ & \\
\hline Nominal $\mathrm{P}(\mathrm{VA})=0.3$ & 87 & 84 & 246 & 243 & 62.6 \\
\hline $\mathrm{P}(\mathrm{VA})=0.4$ & 71 & 66 & 233 & 208 & 61.5 \\
\hline $\mathrm{P}(\mathrm{VA})=0.5$ & 46 & 45 & 141 & 143 & 59.3 \\
\hline
\end{tabular}

Table 11: Pilot visual avoidance sensitivity analysis results 


\begin{tabular}{|l|c|c|c|c|c|}
\hline Failure probability & \multicolumn{2}{|c|}{ Time between NMACs (yrs) } & \multicolumn{2}{c|}{ Time between collisions (yrs) } & Runtime (min) \\
\hline & Mean & $\begin{array}{c}\text { Standard } \\
\text { Deviation }\end{array}$ & Mean & $\begin{array}{c}\text { Standard } \\
\text { Deviation }\end{array}$ & \\
\hline $\begin{array}{l}\text { Nominal } \mathrm{P}(\mathrm{CNMAC}) \\
=0.28\end{array}$ & 87 & 84 & 246 & 243 & 62.6 \\
\hline $\mathrm{P}(\mathrm{CNMAC})=0.4$ & 124 & 103 & 174 & 155 & 60.2 \\
\hline $\mathrm{P}($ CNMAC $)=0.5$ & 155 & 187 & 143 & 176 & 63.2 \\
\hline
\end{tabular}

Table 12: Mid-air collision given NMAC sensitivity analysis results

Lastly, the sensitivity of NMAC and collision estimates to both strategic and tactical conflict detection failure probability was also analyzed. This is important because of a modeling assumption that the probability of detecting a conflict only depends on look-ahead time and no other factor including phase of flight. ${ }^{7}$ As shown in Table 13, changes in NMAC and mid-air collision risk estimates are apparent for just a $20 \%$ increase in detection failure probability. This points to the need for further study to improve estimates of AAC conflict detection probabilities.

\begin{tabular}{|l|c|c|c|c|c|}
\hline Failure probability & \multicolumn{2}{|c|}{ Time between NMACs (yrs) } & \multicolumn{2}{|c|}{ Time between collisions (yrs) } & Runtime (min) \\
\hline & Mean & $\begin{array}{c}\text { Standard } \\
\text { Deviation }\end{array}$ & Mean & $\begin{array}{c}\text { Standard } \\
\text { Deviation }\end{array}$ & \\
\hline $\begin{array}{l}\text { Nominal P(ACD), } \\
\text { Nominal P(TCD) }\end{array}$ & 87 & 84 & 246 & 243 & 62.6 \\
\hline $\begin{array}{l}\text { Nominal P(ACD) } 1.1, \\
\text { Nominal P(TCD) } 1.1\end{array}$ & 72 & 71 & 227 & 209 & 64.0 \\
\hline $\begin{array}{l}\text { Nominal P(ACD) } 1.2, \\
\text { Nominal P(TCD) } \cdot 1.2\end{array}$ & 45 & 43 & 101 & 95 & 67.1 \\
\hline
\end{tabular}

Table 13: Conflict detection sensitivity analysis results

\section{Discussion}

\section{A. Sources of Simulation Runtime Reductions in the Accelerated Monte Carlo Approach}

One main reason for the reduction in simulation runtime with the accelerated Monte Carlo approach is that fewer simulation trials were required. As discussed in Section III, a total of nine Monte Carlo simulations were needed to compute NMAC and collision risk estimates. In some cases, it took up to around $10^{9}$ trials to get at least 100 cases of subfunction failures in a simulation. Recall that these were used as initial conditions in subsequent simulations. However, in most cases, the number of trials needed was several orders of magnitude less. As a result, NMAC and mid-air collision risk estimates could be made with less than half of the $10^{10}$ simulation trials needed in the standard Monte Carlo method.

\section{B. Additional Sensitivity Analysis}

A limited sensitivity analysis was conducted in this paper as a demonstration of an application of the accelerated Monte Carlo approach. It focused on components of AAC that were identified based on fault tree analysis, failure probability magnitude, and intuition. A more thorough sensitivity analysis of all the modeled components of AAC (see Appendix) is a subject for future research.

\section{Confidence Intervals}

The reduction in simulation runtime with the accelerated Monte Carlo approach also facilitates the construction of confidence intervals for NMAC and collision risk estimates in AAC. However, it may be necessary to utilize distributed computing with multiple machines because this can require thousands of simulations. This may be an area of additional work in the future.

\section{Conclusions}

An accelerated Monte Carlo approach that combines features of fault tree and standard Monte Carlo methods was developed to assess the level of safety provided by the Advanced Airspace Concept. Each simulation using the accelerated approach ran in about one hour while providing risk estimates that only differ with those of the standard Monte Carlo method by about $10 \%$. This is more than one order of magnitude faster than the 16 hours required in a 
standard Monte Carlo simulation. It also preserves component-level model fidelity that is difficult to maintain using the standard fault tree method.

Since AAC is a proposed next-generation system with components that are not deployed in the NAS, sensitivity analysis is necessary to identify component failure probabilities that require additional research. The speed and model fidelity of the accelerated Monte Carlo approach facilitates such sensitivity analysis that can be completed in days instead of weeks or months with the standard Monte Carlo method. Results indicate that risk estimates of near mid-air collisions and mid-air collisions are sensitive to transponder, pilot visual avoidance, and conflict detection failure probabilities. Further investigation to obtain more accurate failure probabilities for these three components is needed to generate more accurate estimates of the level of safety provided by AAC.

\section{Appendix}

One of the primary features of the standard Monte Carlo method is its flexibility for component-level simulation. This section describes the individual components of each AAC subfunction and how they interact with one another.

\section{A. Aircraft Locatability}

Flights are locatable if they can be tracked via ADS-B or SSR. A flight is locatable via ADS-B if the following three things are true: 1) it receives position data via GPS, 2) it broadcasts data to ground station via data link, and 3) the ground station successfully sends the flight's data to Host computers. Likewise, a flight is locatable via SSR if the following are true: 1) it receives a signal from ground station to send its data, 2) it uses its transponder to send data to the ground, and 3) its data is sent from ground station to Host computers successfully. If one or both flights are not locatable, then AR and TSAFE cannot handle the conflict. It should be noted that SSR does provide a "skin paint" return in the event of transponder failure that could also be used by air traffic controllers to detect and resolve conflicts, but this feature is not modeled here.

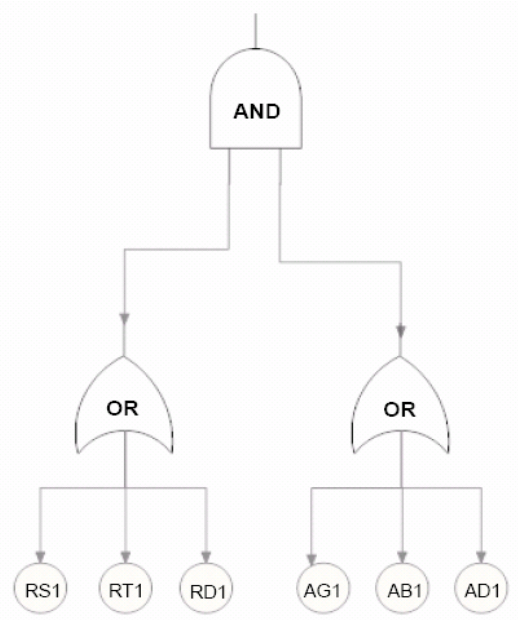

Figure A1: Aircraft 1 locatability

\begin{tabular}{|c|l|l|}
\hline Component & \multicolumn{1}{|c|}{ Description } & \multicolumn{1}{|c|}{ Failure probability } \\
\hline AG1 & ADS-B: AC1 gets position via GPS & 0.0005 (ref. [17]) \\
\hline AB1 & ADS-B: AC1 broadcasts data to ground station & 0.0000097 (ref. [16]) \\
\hline AD1 & ADS-B Ground station sends AC1's data to Host & 0.00002 (ref. [17]) \\
\hline RS1 & Radar: Ground signals AC1 to send data & 0.00682 (ref. [16]) \\
\hline RT1 & Radar: Transponder sends data to ground & N/A (RT1=AB1) \\
\hline RD1 & Radar: Data Set from ground station to Host comps & N/A (RD1=AD1) \\
\hline
\end{tabular}

Table A1: Locatability components and failure probabilities for an aircraft (AC1)

\section{B. AR Functions}

AR is not operational unless both aircraft are locatable via SSR or ADS-B as described in the prior section. If there is track data for both flights, AR resolves the conflict only if flightplan-based trajectories can be computed for 
both flights (FPT1 and FPT2), strategic conflict detection and resolution (ACD and ACR) are successful, and the resolution trajectory can be communicated by voice or datalink.

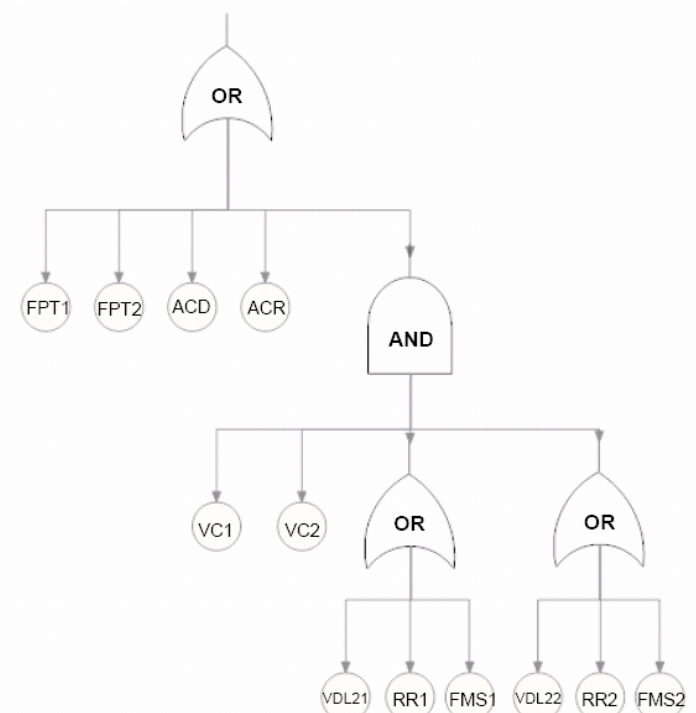

Figure 2: AR detection, resolution, and communication

\begin{tabular}{|c|l|l|}
\hline Component & \multicolumn{1}{|c|}{ Description } & \multicolumn{1}{c|}{ Failure probability } \\
\hline FPT1 & Generate 4-D flight plan trajectory (AC1) & 0.000001 (assumed) \\
\hline FPT2 & Generate 4-D flight plan trajectory (AC2) & 0.000001 (assumed) \\
\hline ACD & Auto-Resolver: Conflict detection module & Varies (see Appendix, sec. H of ref. [7]) \\
\hline ACR & Auto-Resolver: Conflict resolution module & 0.000001 (ref. [6]) \\
\hline VDL21 & VDL2: Resolution upload via data link (AC1) & 0.00004 (ref. [18]) \\
\hline VDL22 & VDL2: Resolution upload via data link (AC2) & 0.00004 (ref. [18]) \\
\hline VC1 & AC1's data sent to Host via voice communication & 0.00055 (ref. [16]) \\
\hline VC2 & AC2's data sent to Host via voice communication & 0.00055 (ref. [16]) \\
\hline RR1 & Onboard resolution reader (AC1) & 0.000001 (ref. [18]) \\
\hline RR2 & Onboard resolution reader (AC2) & 0.000001 (ref. [18]) \\
\hline FMS1 & Onboard resolution trajectory generator (AC1) & 0.000097 (proxy from ref. [16]) \\
\hline FMS2 & Onboard resolution trajectory generator (AC2) & 0.000097 (proxy from ref. [16]) \\
\hline
\end{tabular}

\section{Table A2: AR components and failure probabilities}

\section{TSAFE Functions}

If both flights are locatable but AR fails to resolve the conflict, then TSAFE becomes responsible for handling it. The TSAFE fault tree is similar to the AR one in that it only resolves the conflict if dead-reckoning trajectories can be calculated for both flights (DRT1 and DRT2), tactical conflict detection and resolution (TCD and TCR) are successful, and the resolution trajectory can be communicated via Mode S to an on-board resolution reader that translates the maneuver and produces an aural command for the pilot to execute. 


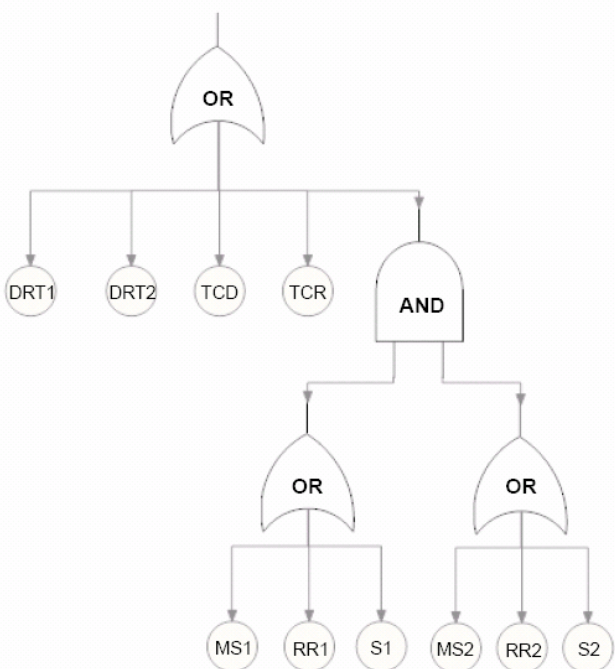

Figure A3: TSAFE detection, resolution, and communication

\begin{tabular}{|c|l|l|}
\hline Component & \multicolumn{1}{|c|}{ Description } & \multicolumn{1}{|c|}{ Failure probability } \\
\hline DRT1 & Generate 4-D dead reckoning trajectory (AC1) & 0.000001 (assumed) \\
\hline DRT2 & Generate 4-D dead reckoning trajectory (AC2) & 0.000001 (assumed) \\
\hline MS1 & Mode S: Resolution upload via data link (AC1) & N/A (MS1=AB1) \\
\hline MS2 & Mode S: Resolution upload via data link (AC2) & N/A (MS2=AB2) \\
\hline TCD & TSAFE: Conflict detection module & Varies (see Appendix, sec. H of ref. [7]) \\
\hline TCR & TSAFE: Conflict resolution module & 0.000001 (assumed) \\
\hline RR1 & Onboard resolution reader (AC1) & N/A (Same as RR1 in Table A2) \\
\hline RR2 & Onboard resolution reader (AC2) & N/A (Same as RR2 in Table A2) \\
\hline S1 & Onboard speaker (AC1) & 0.000001 (assumed) \\
\hline S2 & Onboard speaker (AC2) & 0.000001 (assumed) \\
\hline
\end{tabular}

Table A3: TSAFE components and failure probabilities

\section{TCAS and Pilot Visual Avoidance}

The TCAS safety layer shares two components with other AAC safety layers: 1) mode S transponder, and 2) cockpit speaker. If either of these components fails in a safety layer upstream or any other TCAS subcomponent fails (i.e., on-board TCAS computer, on-board radar, etc. ${ }^{7,13}$ ), then TCAS fails and there is a $30 \%$ chance that pilots will not be able to visually detect and avoid the NMAC. ${ }^{6}$ In that case, there is a $28 \%$ chance of collision. ${ }^{7}$

\begin{tabular}{|c|l|l|}
\hline Component & \multicolumn{1}{|c|}{ Description } & \multicolumn{1}{|c|}{ Failure probability } \\
\hline MS1 & Mode S: Resolution upload via data link (AC1) & N/A (same as MS1 above) \\
\hline MS2 & Mode S: Resolution upload via data link (AC2) & N/A (same as MS2 above) \\
\hline S1 & Onboard speaker (AC1) & N/A (same as S1 above) \\
\hline S2 & Onboard speaker (AC2) & N/A (same as S1 above) \\
\hline TCAS1 $1_{\text {Other }}$ & Non-transponder, non-speaker TCAS components (AC1) & 0.1002 (ref. [7], based on ref. [6], [18]) \\
\hline TCAS2 ${ }_{\text {Other }}$ & Non-transponder, non-speaker TCAS components (AC2) & 0.1002 (ref. [7], based on ref. [6], [18]) \\
\hline VA & Pilot detects and resolves the conflict via visual avoidance & 0.30 (ref. [6]) \\
\hline CNMAC & Collision given NMAC & 0.28 (ref. [7]) \\
\hline
\end{tabular}

Table A4: TCAS, pilot visual avoidance, and collision failure probabilities

\section{Acknowledgments}

The author would like to thank Heinz Erzberger, Jerry Welch, Dave McNally, Jeffery Schroeder, Todd Farley, Russell Paielli, Todd Lauderdale, John Andrews, Elisabeth Paté-Cornell, and the Stanford University Management 
Science \& Engineering (MS\&E) 250B class especially David Blum, Tamika Rentas, Ye He, and Xi Wang for their insightful comments and suggestions.

\section{References}

${ }^{1}$ Joint Planning and Development Office, “Next Generation Air Transportation System Integrated Plan,” Dec. 12, 2004.

${ }^{2}$ Consiglio, M.C., Hoadley, S.T., Wing, D.J., Baxley, B.T., "Safety Performance of Airborne Separation: Preliminary Baseline Testing," $7^{\text {th }}$ AIAA Aviation Technology, Integration, and Operations Conference, Sep. 18-20, 2007. 2001.

${ }^{3}$ Erzberger, H., "The Automated Airspace Concept," $4^{\text {th }}$ USA/Europe Air Traffic Management R\&D Seminar, Dec. 3-7,

${ }^{4}$ Erzberger, H., Paielli, R.A., “Concept for Next Generation Air Traffic Control System,” Air Traffic Control Quarterly, Vol. 10(4), pp. 355-378, 2002.

${ }^{5}$ Erzberger, H., "Transforming the NAS: The Next Generation Air Traffic Control System," $24^{\text {th }}$ International Congress of the Aeronautical Sciences, Aug. 29 - Sep. 3, 2004.

${ }^{6}$ Andrews, J.W., Erzberger, H., Welch, J.D., "Safety Analysis for Advanced Separation Concepts," Air Traffic Control Quarterly, Vol. 14(1), pp. 5-24, 2006.

${ }^{7}$ Blum, D, Thipphavong, D., Rentas, T., He, Y., Wang, X., "Safety Analysis of the Automated Airspace Concept using Monte Carlo Simulation," AIAA Guidance, Navigation, and Control Conference, Aug. 2-5, 2010 (to be published).

${ }^{8}$ Farley, T., Kupfer, M., Erzberger, H., “Automated Conflict Resolution: A Simulation Evaluation Under High Demand Including Merging Arrivals," $7^{\text {th }}$ AIAA Aviation Technology Integration and Operations Conference, Sep. 18-20, 2007.

${ }^{9}$ Kupfer, M., Farley, T., Chu, Y., Erzberger, H. (2008), “Automated Conflict Resolution - A Simulation-Based Sensitivity Study of Airspace and Demand," $26^{\text {th }}$ International Congress of the Aeronautical Sciences, Sep. 14-19, 2008.

${ }^{10}$ Paielli, R.A., Erzberger, H., Chiu, D., Heere, K.R., "Tactical Conflict Alerting Aid for Air Traffic Controllers," AIAA Journal of Guidance, Control and Dynamics, Vol.32(1), Jan.-Feb. 2009.

${ }^{11}$ Paielli, R.A., "Tactical Conflict Resolution using Vertical Maneuvers in Enroute Airspace," AIAA Journal of Aircraft, Vol.45(6), Nov-Dec 2008.

${ }^{12}$ Erzberger, H., Heere, K., "Algorithm and Operational Concept for Resolving Short-Range Conflicts," $26^{\text {th }}$ International Congress of the Aeronautical Sciences, Sep. 14-19, 2008.

${ }^{13}$ U.S. Department of Transportation and Federal Aviation Administration, “Introduction to TCAS II: Version 7,” Nov. 2000.

${ }^{14}$ Blom, H.A.P., Obbink, B.K., Bakker, G.J.B., "Simulated Collision Risk of an Uncoordinated Airborne Self Separation Concept of Operation," $7^{\text {th }}$ EUROCONTROL Innovative ATM Research Workshop and Exhibition, pp. 33-42, Dec. 2-4, 2008.

${ }^{15}$ Blom, H.A.P., Krystul, J., Bakker, G.J.B., Klompstra, M.B., Obbink, B.K., "Free Flight Collision Risk Estimation by Sequential Monte Carlo Simulation," Stochastic Hybrid Systems: Recent Developments and Research Trends, edited by C.G. Cassandras and J. Lygeros, CRC Press, 2006.

\footnotetext{
${ }^{16}$ Hemm, R.V., Busick, A.C., "Safety Analysis of the Separation Assurance Function in Today's National Airspace System," Report NS801T2, Jan. 2009.

${ }^{17}$ Hammer, J., Caligaris, G., Llobet, M., "Safety Analysis Methodology for ADS-B Based Surveillance Applications," $7^{\text {th }}$ USA/Europe ATM 2007 R\&D Seminar, Jul. 2-5, 2007.

${ }^{18}$ Eriksson, M., Lundmark, J., "Technical Verification and Validation of ADS-B/VDL Mode 4 for A-SMGCS," SCAA_NUP_WP33_TVV_ADS_B_A-SMGCS_1.0, Dec. 2002.
} 